\title{
Aclimatação de mudas de acariquara à alta irradiância
}

\author{
Nilvanda dos Santos Magalhães ${ }^{(1)}$, Ricardo Antonio Marenco ${ }^{(2)}$ e Keila Rêgo Mendes ${ }^{(1)}$
}

(1)Instituto Nacional de Pesquisas da Amazônia (Inpa), Curso de Pós-Graduação em Botânica, Caixa Postal 478, CEP 69011-970 Manaus, AM. E-mail: nilvanda3@hotmail.com, keilastm@hotmail.com ${ }^{(2)}$ Inpa, Coordenação de Pesquisas em Silvicultura Tropical. E-mail: rmarenco@inpa.gov.br

Resumo - O objetivo deste trabalho foi determinar as mudanças fisiológicas que ocorrem em acariquara (Minquartia guianensis) durante o processo de aclimatação à alta irradiância, bem como a estratégia de aclimatação dessa espécie. Plantas mantidas em baixa irradiância foram transferidas para alta irradiância por 290 dias. Durante esse período, foi medida a relação entre fluorescência variável e máxima $\left(\mathrm{F}_{\mathrm{v}} / \mathrm{F}_{\mathrm{m}}\right)$, em folhas desenvolvidas à sombra e, após a senescência prematura por foto-oxidação, em folhas aclimatadas ao sol. Ao final do experimento, foram determinadas as características fotossintéticas e anatômicas da folha. A exposição à alta irradiância causou, logo após a transferência, forte fotoinibição e foto-oxidação parcial da folhagem, mas não provocou a morte da planta. Folhas produzidas no ambiente ensolarado apresentaram valores de $\mathrm{F}_{\mathrm{v}} / \mathrm{F}_{\mathrm{m}}$ similares aos do controle. A fotossíntese saturada por luz e a fotossíntese saturada por $\mathrm{CO}_{2}$ foram 90 e $50 \%$ maiores em plantas aclimatadas à alta irradiância. A velocidade máxima de carboxilação da rubisco e a taxa máxima de regeneração da ribulose bisfosfato seguiram a mesma tendência. Folhas produzidas ao sol apresentaram maior densidade estomática e maior espessura foliar. A produção de folhas novas é a principal estratégia de aclimatação da acariquara à alta irradiância.

Termos para indexação: Minquartia guianensis, características da folha, características fotossintéticas, fluorescência da clorofila, fotoinibição.

\section{Acclimation of manwood seedlings to full sunlight}

\begin{abstract}
The aim of this work was to determine the physiological changes that occur in manwood (Minquartia guianensis) during the acclimation process to high irradiance, and also to determine the acclimation strategy of this species. Plants kept in low light were transferred to high irradiance for 290 days. During this period the ratio between variable fluorescence and maximum fluorescence $\left(\mathrm{F}_{\mathrm{v}} / \mathrm{F}_{\mathrm{m}}\right)$ was measured in leaves developed in the shade, and after premature senescence due to photooxidation, in sun-acclimated leaves. At the end of the experimental period the anatomic and photosynthetic characteristics of leaves were determined. Exposure to high irradiance caused, just after transferring, strong photoinhibition and partial photooxidation, but did not cause plant death. Leaves produced in sunny environment showed $\mathrm{F}_{\mathrm{v}} / \mathrm{F}_{\mathrm{m}}$ similar to that of control plants. Light-saturated photosynthesis and $\mathrm{CO}_{2}$ saturated-photosynthesis were 90 and $50 \%$ higher in plants acclimated to high irradiance. The maximum carboxylation velocity of rubisco and the maximum rate of ribulose bisphosphate regeneration followed the same trend. Leaves produced under sunlight had higher stomatal density and increased leaf thickness. The production of new leaves is the main acclimation strategy to high irradiance in manwood.

Index terms: Minquartia guianensis, leaf traits, photosynthetic characteristics, chlorophyll fluorescence, photoinhibition.
\end{abstract}

\section{Introdução}

A luz é o fator limitante mais importante no crescimento de árvores da floresta tropical na fase juvenil (arvoretas), o que torna as aberturas do dossel e as clareiras essenciais para o crescimento e a sobrevivência de arvoretas e, consequentemente, para a dinâmica da floresta. No entanto, o aumento súbito da irradiância durante a formação de aberturas e clareiras pode induzir a fotoinibição da fotossíntese em plantas aclimatadas ao sub-bosque (Houter \& Pons, 2005) e, em casos extremos, resultar na foto-oxidação do tecido foliar.

De acordo com a forma com que respondem a alterações na irradiância, as plantas podem ser classificadas em plantas de sol e plantas de sombra (Björkman, 1981). Arvoretas de espécies tolerantes ao sol (pioneiras) e tolerantes à sombra (clímax) normalmente reagem de forma diferente às alterações no ambiente luminoso (Oguchi et al., 2005). Espécies do mesmo grupo sucessional e até 
ecótipos da mesma espécie não reagem de igual forma às alterações na irradiância do entorno (Lovelock et al., 1994). Plantas desenvolvidas exclusivamente à sombra têm capacidade limitada para aumentar as taxas de fotossíntese em ambientes de alta irradiância devido à incapacidade de aumentar a atividade da rubisco, enquanto em plantas desenvolvidas ao sol ocorre o contrário. Os fatores que limitam a fotossíntese variam de acordo com o regime de luz no ambiente de crescimento. Plantas desenvolvidas à sombra investem mais em complexos coletores de luz e plantas desenvolvidas ao sol, em proteínas do ciclo de Calvin e do transporte de elétrons (Laisk et al., 2005). Dessa forma, variações no regime luminoso durante o crescimento normalmente levam a diferenças nas taxas de fotossíntese (A), em razão das diferenças na velocidade máxima de carboxilação da rubisco $\left(\mathrm{V}_{\mathrm{c} \text {-máx. }}\right)$ e na taxa máxima de regeneração da ribulose bisfosfato, $\operatorname{RuBP},\left(\mathrm{J}_{\text {máx. }}\right)$, dependente do transporte de elétrons, bem como das diferenças nas taxas de difusão de $\mathrm{CO}_{2}$ para os cloroplastos (Björkman, 1981). Segundo Farquhar et al. (1980), o valor de A representa o valor mínimo de dois fatores limitantes: a atividade da rubisco $\left(A_{c}\right)$ e a taxa de regeneração da $\operatorname{RuBP}\left(A_{j}\right)$. Isto é, $A=\min \left\{A_{c}, A_{j}\right\}-R_{d}$, em que $R_{d}$ indica a taxa de respiração da folha na presença de luz.

A resposta da fotossíntese à irradiância é comumente descrita por uma hipérbole não retangular que inclui os parâmetros teta $(\Theta)$ e fi $(\Phi)$, em que $\Theta$ representa a convexidade da curva e $\Phi$, o rendimento quântico máximo (Ogren, 1993). Em condições naturais, a taxa de fotossíntese é geralmente limitada pela luz, por isso $\Phi$ e $\Theta$ são parâmetros importantes. Em plantas $\mathrm{C}_{3} \mathrm{em}$ concentração de $\mathrm{CO}_{2}$ ambiente, $\Phi$ é uma função dessa concentração nos espaços intercelulares $\left(\mathrm{C}_{\mathrm{i}}\right)$ e pode ser diminuído pela alta irradiância devido à fotoinibição. Em alta irradiância, as folhas absorvem mais energia radiante que a capacidade de processamento do aparato fotossintético, e o excesso de energia radiante pode levar à fotoinibição da fotossíntese, ou seja, à redução nos valores de $\Phi$ (Choudhury \& Behera, 2001; Demmig-Adams $\&$ Adams, 2006). Como há uma relação linear entre $\Phi$ e $\mathrm{F}_{\mathrm{v}} / \mathrm{F}_{\mathrm{m}}$, em que $\mathrm{F}_{\mathrm{v}}$ indica a fluorescência variável e $\mathrm{F}_{\mathrm{m}}$ a fluorecência máxima (a diferença entre $\mathrm{F}_{\mathrm{m}}$ e a $\mathrm{F}$ inicial, $\mathrm{F}_{\mathrm{o}}$ ) (Genty et al., 1989), essa relação é comumente utilizada como estimativa da fotoinibição. Além da irradiância excessiva, o estresse hídrico e aumentos na temperatura (aumento na fotorrespiração) também podem levar a decréscimos em $\Phi$. No grupo de plantas tolerantes à sombra, como a acariquara (Minquartia guianensis Aubl.), as estratégias de aclimatação à alta irradiância variam entre espécies e até entre ecótipos de uma mesma espécie (Björkman, 1981).

A acariquara é uma árvore de dossel (cresce cerca de $30 \mathrm{~m}$ de altura), possui madeira com coloração marrom-escura, dura, pesada e muito durável. Seu tronco é bastante irregular e sua madeira, muito resistente ao apodrecimento e a ataques de cupins, é muito usada na indústria, na fabricação de pisos e forros. A acariquara cresce bem em florestas de várzea com precipitação anual de 2.000 a $4.000 \mathrm{~mm}$, e suas sementes não regeneram em campos abertos, o que a torna uma espécie tolerante à sombra e que pode ser classificada como espécie do estádio tardio de sucessão.

No presente trabalho, partiu-se da premissa de que folhas de mudas de acariquara desenvolvidas à sombra apresentam alta plasticidade fisiológica, de modo que continuam a manter taxas similares de fotossíntese após a transferência para alta irradiância sem mostrar perda significativa de folhas.

O objetivo deste trabalho foi determinar as mudanças fisiológicas que ocorrem em acariquara (M. guianensis) durante o processo de aclimatação à alta irradiância, bem como a estratégia de aclimatação dessa espécie.

\section{Material e Métodos}

O presente estudo foi realizado no campus $\mathrm{V}-8$ do Instituto Nacional de Pesquisas da Amazônia (Inpa)

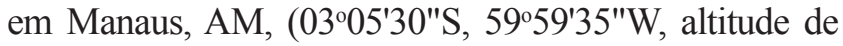
$51 \mathrm{~m}$ ) entre setembro de 2007 e julho de 2008. Foram utilizadas mudas de acariquara ( $M$. guianensis) de aproximadamente um ano de idade e $12 \mathrm{~cm}$ de altura, produzidas a partir de sementes e cultivadas em vasos de plástico (4 L) em substrato formado por uma mistura de terra compostada (90\%), areia $(7 \%)$ e vermiculita $(3 \%)$. $\mathrm{O}$ substrato foi adubado $\left(5 \mathrm{~g} \mathrm{~kg}^{-1}\right)$ com um fertilizante de liberação lenta (Basacote). As mudas foram mantidas em baixa irradiância $\left(0,30 \mathrm{~mol} \mathrm{~m}^{-2}\right.$ dia $\left.^{-1}\right)$ até o início do experimento.

Os tratamentos foram constituídos por um grupo de dez plantas expostas durante 290 dias à alta irradiância (céu aberto). O controle foi constituído por outro grupo de plantas (dez mudas) mantidas sob a sombra de árvores adultas e debaixo de um telado, para aumentar 
o sombreamento para níveis de irradiância comparáveis aos encontrados no ambiente natural (Marenco \& Vieira, 2005). Airradiância (Q) recebida pelas plantas em aclimatação durante o experimento foi de 21,45 $\mathrm{mol} \mathrm{m}^{-2} \mathrm{dia}^{-1}$, com amplitude de 8,0 a $35,1 \mathrm{~mol} \mathrm{~m}^{-2}$ dia $^{-1}$ e picos de irradiância de 1.000 a $1.200 \mu \mathrm{mol} \mathrm{m}^{-2} \mathrm{~s}^{-1}$. No controle, a irradiância foi de $0,30 \mathrm{~mol} \mathrm{~m}^{-2} \mathrm{dia}^{-1}$, com amplitude de 0,10 a $0,5 \mathrm{~mol} \mathrm{~m}^{-2} \mathrm{dia}^{-1}$. Durante o dia, a temperatura e a umidade do ar foram de 26 a $30^{\circ} \mathrm{C}$ e de 72 a $96 \%$, respectivamente, no controle e de 26 a $32^{\circ} \mathrm{C}$ e de 50 a $91 \%$ no tratamento em alta irradiância.

A densidade de fluxo de fótons (Q) foi medida utilizando um sensor quântico (LI-191SA, Li-Cor, Lincoln, Nebraska, EUA) conectado a um coletor de dados (LI-1000, Li-Cor). Os valores de Q foram coletados em intervalos de 15 minutos durante o período experimental. A umidade e a temperatura do ar foram medidas com um termo-higrômetro digital (Incoterm, Brasil) em dias selecionados ao acaso, em intervalos de $30 \mathrm{~min}$.

Afluorescência da clorofila foi mensurada em intervalos de dois a três dias desde o início até o final do experimento (totalizando 119 dias amostrados) para determinar o efeito da alta irradiância na fotoinibição da fotossíntese (inferida pela relação $\left.\mathrm{F}_{\mathrm{v}} / \mathrm{F}_{\mathrm{m}}\right)$. Durante o período de aclimatação, as folhas que sofreram foto-oxidação (morte do tecido) ou experimentaram senescência foram substituídas por folhas expandidas produzidas no novo regime de luz (após duas a três semanas do início do experimento, dependendo do grau de desenvolvimento da folha por ocasião da transferência ao ambiente aberto).

A fluorescência da clorofila foi mensurada logo ao amanhecer com um fluorômetro (PEA, MK2, 9600, Hansatech, UK) após 15 min de adaptação ao escuro. Foram mensuradas a fluorescência inicial $\left(F_{o}\right)$ e máxima $\left(F_{m}\right)$ e a eficiência quântica máxima do fotossistema (relação $F_{v} / F_{m}$ ).

Ao final do período de aclimatação, foram medidas as trocas gasosas, o teor de clorofila, a espessura da folha, a densidade estomática, o comprimento das células-guarda e a área foliar específica (AFE, relação entre área e massa foliar). Também foram determinados a altura da planta e o diâmetro do caule a $5 \mathrm{~cm}$ do coleto das plantas. As trocas gasosas foram determinadas em quatro plantas com duas folhas completamente expandidas e bom estado fitossanitário, por tratamento. Foi utilizado um medidor de fotossíntese (LI-6400, Li-Cor) com controle independente de luz (Li-6400-02B) e de $\mathrm{CO}_{2}(6400-01)$. $\mathrm{A}$ resposta da fotossíntese à irradiância $[$ curva $\mathrm{A}(\mathrm{Q})] \mathrm{e}$ à concentração intracelular de $\mathrm{CO}_{2}(\mathrm{Ci})_{\mathrm{i}}$ [curva $\mathrm{A}\left(\mathrm{C}_{\mathrm{i}}\right)$ ] foi gerada conforme descrito previamente (Marenco et al., 2001). Os dados de trocas gasosas foram obtidos quando o coeficiente de variação total foi menor que 0,7\% (Long \& Bernacchi, 2003). A partir da curva $A(Q)$, foram determinados a fotossíntese saturada por luz $\left(\mathrm{A}_{\text {máx. }}\right), \Phi, \Theta$ e a irradiância de compensação $\left(\mathrm{I}_{\mathrm{c}}\right)$. Dados da curva $\mathrm{A}(\mathrm{Ci})$ foram utilizados para determinar fotossíntese saturada por luz e por $\mathrm{CO}_{2}\left(\mathrm{~A}_{\text {pot. }}\right), \mathrm{V}_{\text {c-máx. }}$, $J_{\text {máx. }}$ e o ponto de compensação de $\mathrm{CO}_{2}(\Gamma)$. Os valores de $A_{\text {máx. }}$ e $A_{\text {pot. }}$ foram determinados em luz saturante $1.000 \mu \mathrm{mol} \mathrm{m} \mathrm{m}^{-2} \mathrm{~s}^{-1}$ e concentração $\mathrm{CO}_{2}$ de $380\left(\mathrm{~A}_{\text {máx. }}\right)$ ou $2.000 \mu \mathrm{mol} \mathrm{mol}{ }^{-1}\left(\mathrm{~A}_{\text {pot. }}\right)$. Durante as medições, a umidade relativa do ar, o deficit de pressão de vapor (DPV) e a temperatura oscilaram conforme as condições do ambiente; a temperatura do ar oscilou entre 29 e $30^{\circ} \mathrm{C}$ e o DPV, entre 1,10 e $2,17 \mathrm{kPa}$.

Os dados de $\mathrm{A}(\mathrm{Q})$ foram ajustados com o modelo da hipérbole não retangular $\left[\Theta \mathrm{A}_{\mathrm{g}}{ }^{2}-\left(\Phi \mathrm{Q}+\mathrm{A}_{\text {gmáx. }}\right) \mathrm{A}_{\mathrm{g}}+\Phi \mathrm{Q} \mathrm{A}_{\text {gmáx. }}=0\right]$ (equação 1). Nesta equação, $\mathrm{A}_{\mathrm{g}}$ representa a fotossíntese bruta $\left(A_{g}=A+R_{d}\right)$. A equação 1 é uma quadrática de segunda ordem da forma $y=a x^{2}+b x+c=0$, que pode ser resolvida para $x=\left[-b \pm\left(b^{2}-4 a c\right)^{0,5}\right] / 2 a$ (equação 2 ). Os coeficientes $\mathrm{a}, \mathrm{b}$ e $\mathrm{c}$ da equação 2 representam: teta $(\Theta),\left(\Phi \mathrm{Q}+\mathrm{A}_{\text {gmáx. }}\right)$ e $\Phi \mathrm{QA}_{\text {gmáx., }}$ respectivamente. Substituindo-os na equação 2, tem-se:

$\mathrm{A}=\left\{\left[\left(\Phi \mathrm{Q}+\mathrm{A}_{\text {máx. }}+\mathrm{R}_{\mathrm{d}}\right)-\left(\left(\Phi \mathrm{Q}+\mathrm{A}_{\text {máx. }}+\mathrm{R}_{\mathrm{d}}\right)^{2}\right.\right.\right.$ - 4ФQ $\left.\left.\Theta\left(\mathrm{A}_{\text {máx. }}+\mathrm{R}_{\mathrm{d}}\right)\right)^{0,5} \mathrm{~J} / 2 \Theta\right\}$ - $\mathrm{R}_{\mathrm{d}}$ (equação 3).

As taxas de fotossíntese em função da atividade da rubisco $\left(\mathrm{A}_{\mathrm{c}}\right)$ e da taxa de transporte de elétrons $\left(\mathrm{A}_{\mathrm{j}}\right)$ foram estimadas de acordo com as equações a seguir (Farquhar et al., 1980): $\mathrm{A}_{\mathrm{c}}=\left[\mathrm{V}_{\mathrm{c} \text {-máx. }}\left(\mathrm{C}_{\mathrm{i}}-\Gamma^{*}\right)\right] /\left[\mathrm{C}_{\mathrm{i}}+\mathrm{K}_{\mathrm{c}}\left(1+\mathrm{O} / \mathrm{K}_{\mathrm{o}}\right)\right]$ (equação 4) e $\mathrm{A}_{\mathrm{j}}=\left[\mathrm{J}_{\text {máx. }}\left(\mathrm{C}_{\mathrm{i}}-\Gamma^{*}\right)\right] /\left(\left[4 \mathrm{C}_{\mathrm{i}}+8 \Gamma^{*}\right)\right]$ (equação 5), em que $\Gamma^{*}$ é o ponto de compensação de $\mathrm{CO}_{2}$ na ausência de respiração e na presença de luz; $\mathrm{K}_{\mathrm{c}}$ e $\mathrm{K}_{\mathrm{o}}$ representam as constantes de Michaelis-Mentem da rubisco para $\mathrm{CO}_{2}$ e $\mathrm{O}_{2}$, respectivamente, e $\mathrm{O}$ representa a concentração de oxigênio nos espaços intercelulares. $\Gamma^{*}=36,9+1,88(\mathrm{~T}-25)+0,036(\mathrm{~T}-25)^{2}$ (equação 6), em que $\mathrm{T}$ é a temperatura em graus Celsius. Os valores de $\mathrm{V}_{\text {c-máx. }}$ e $\mathrm{J}_{\text {máx. }}$ foram normalizados a $25^{\circ} \mathrm{C}$ com uso das equações descritas por Medlyn et al. (1999).

O teor de clorofila foi determinado após a extração dos pigmentos cloroplastídicos em acetona 80\%, conforme descrito anteriormente (Jesus \& Marenco, 2008). A espessura foliar foi medida, evitando-se as nervuras principais, com um paquímetro digital em folhas frescas e após secagem a $72^{\circ} \mathrm{C}$ em estufa, até 
atingirem massa constante. A densidade estomática foi determinada em quatro folhas por planta e dez plantas por tratamento (aclimatadas e controle), com uso de impressões da superfície foliar obtidas com esmalte incolor. A contagem de estômatos foi feita com microscópio em magnificação de 400x e o comprimento das células-guarda (CG) foi mensurado a $1.000 x$. Os dados dos parâmetros estudados foram submetidos à análise de variância (ANOVA). O programa SAEG 9.0 da Universidade Federal de Viçosa foi utilizado para ajustar os parâmetros $(\Theta$ e $\left.A_{\text {máx. }}\right)$ da curva $A(Q)$. $O$ valor de $\Phi$ foi determinado pela análise de regressão com as irradiâncias inferiores a $60 \mu \mathrm{mol} \mathrm{m} \mathrm{m}^{-2} \mathrm{~s}^{-1}$. O efeito do período de aclimatação na fluorescência foi analisado por meio do teste $t$ para observações pareadas (controle e alta irradiância com $118 \mathrm{gl})$.

\section{Resultados e Discussão}

A partir do primeiro dia de exposição ao sol, as folhas apresentaram forte fotoinibição, que evoluiu para foto-oxidação nas folhas superiores da planta. A foto-oxidação manifestou-se como manchas cloróticas que evoluíram para manchas necróticas em cinco a seis dias após o início do tratamento (Figura 1), seguida de abscisão das folhas que apresentaram áreas necróticas muito extensas, superiores a $50 \%$ da área foliar. Assim, cerca de $30 \%$ das folhas presentes antes do tratamento colapsaram até o final da segunda semana no tratamento com alta luminosidade (Figura 1 E). Contudo, algumas folhas do terço inferior permaneceram na planta durante a maior parte do experimento. Embora a irradiância intensa tenha causado foto-oxidação em boa parte da folhagem desenvolvida à sombra, a mortalidade em plantas aclimatadas à luz solar plena foi nula.

No grupo de plantas tolerantes à sombra, as estratégias de aclimatação à alta irradiância variam entre espécies. Após a transferência à alta irradiância, Hybanthus prunifolius sofre fotoinibição severa e perda quase total das folhas desenvolvidas à sombra. Já em Ouratea lucens, a transferência à alta irradiância causa apenas fotoinibição moderada e retém a maioria das folhas produzidas em baixa irradiância (Kursar \& Coley, 1999). Em algumas espécies, a aclimatação à alta irradiância pode ocorrer na própria folha (Oguchi et al., 2005). Porém, em outras espécies, a produção de novas folhas com morfologia e fisiologia adequadas ao novo ambiente é a principal estratégia do processo de aclimatação (Kursar \& Coley, 1999), o que parece ser o caso de acariquara.

A transferência das mudas desenvolvidas à sombra para a alta irradiância causou efeito significativo nos valores da fluorescência ( $\mathrm{p} \leq 0,01$, Figura 2$)$. A flurescência inicial $\left(\mathrm{F}_{\mathrm{o}}\right)$ aumentou nas primeiras semanas à proporção que folhas presentes na planta experimentavam fotoinibição (baixa relação $\mathrm{F}_{\mathrm{v}} / \mathrm{F}_{\mathrm{m}}$ ). Posteriormente, a $\mathrm{F}_{\mathrm{o}}$ declinou de forma gradual até o final do quarto mês do início do experimento, aproximando-se dos valores do controle (Figura 2 A). Nas plantas expostas à alta irradiância houve rápido decréscimo nos valores de fluorescência máxima $\left(\mathrm{F}_{\mathrm{m}}\right)$, seguido de aumento gradativo até atingir, aos 30 dias, os mesmos valores observados ao final do período de aclimatação; porém, sem atingir os valores do controle (Figura 2 B). Os valores de $\mathrm{F}_{\mathrm{v}} / \mathrm{F}_{\mathrm{m}}$ apresentaram variação similar aos observados para $\mathrm{F}_{\mathrm{m}}$. Isto é, houve uma redução brusca nos primeiros três dias de exposição à alta irradiância (Figura 2 C), seguida de recuperação gradual
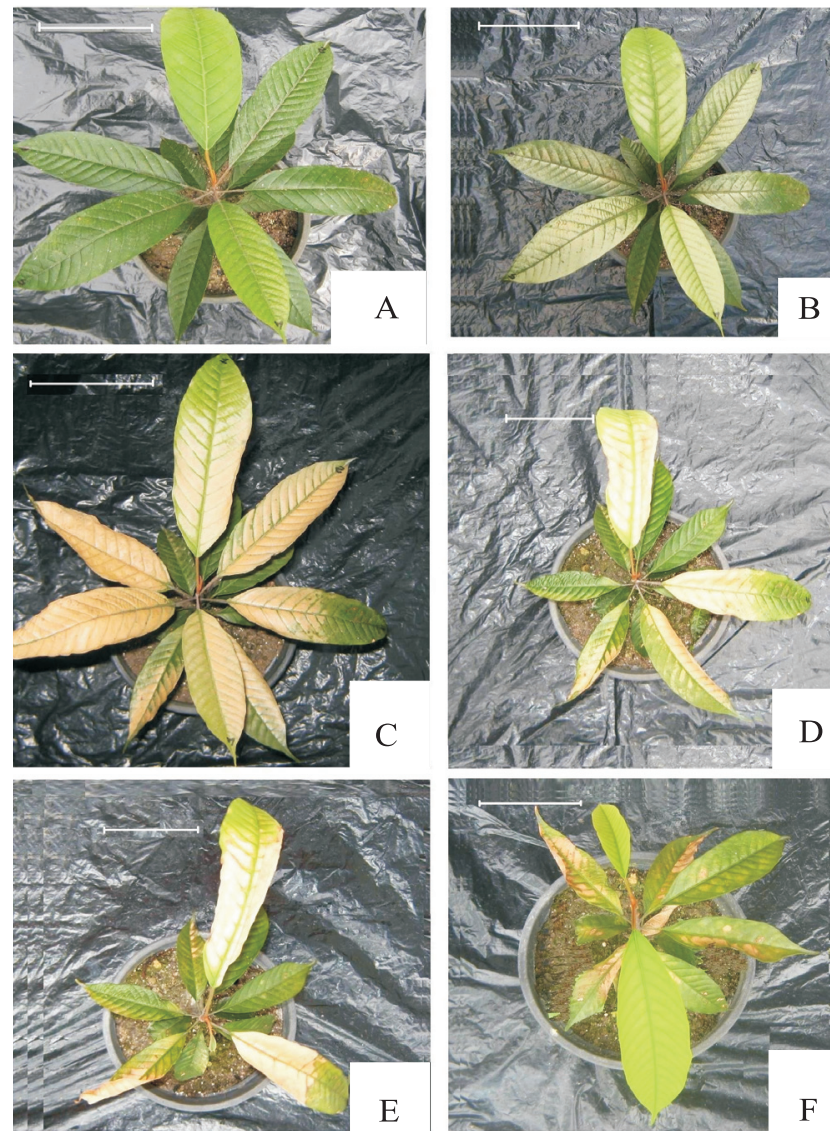

Figura 1. Foto-oxidação em folhas de acariquara (Minquartia guianensis), em resposta ao estresse luminoso. A, controle $\left(0,30 \mathrm{~mol} \mathrm{~m}^{-2} \mathrm{dia}^{-1}\right) ; \mathrm{B}$, plantas expostas à luz solar plena por quatro dias; C, seis dias; D, dez dias; E, 14 dias e F, 30 dias. 


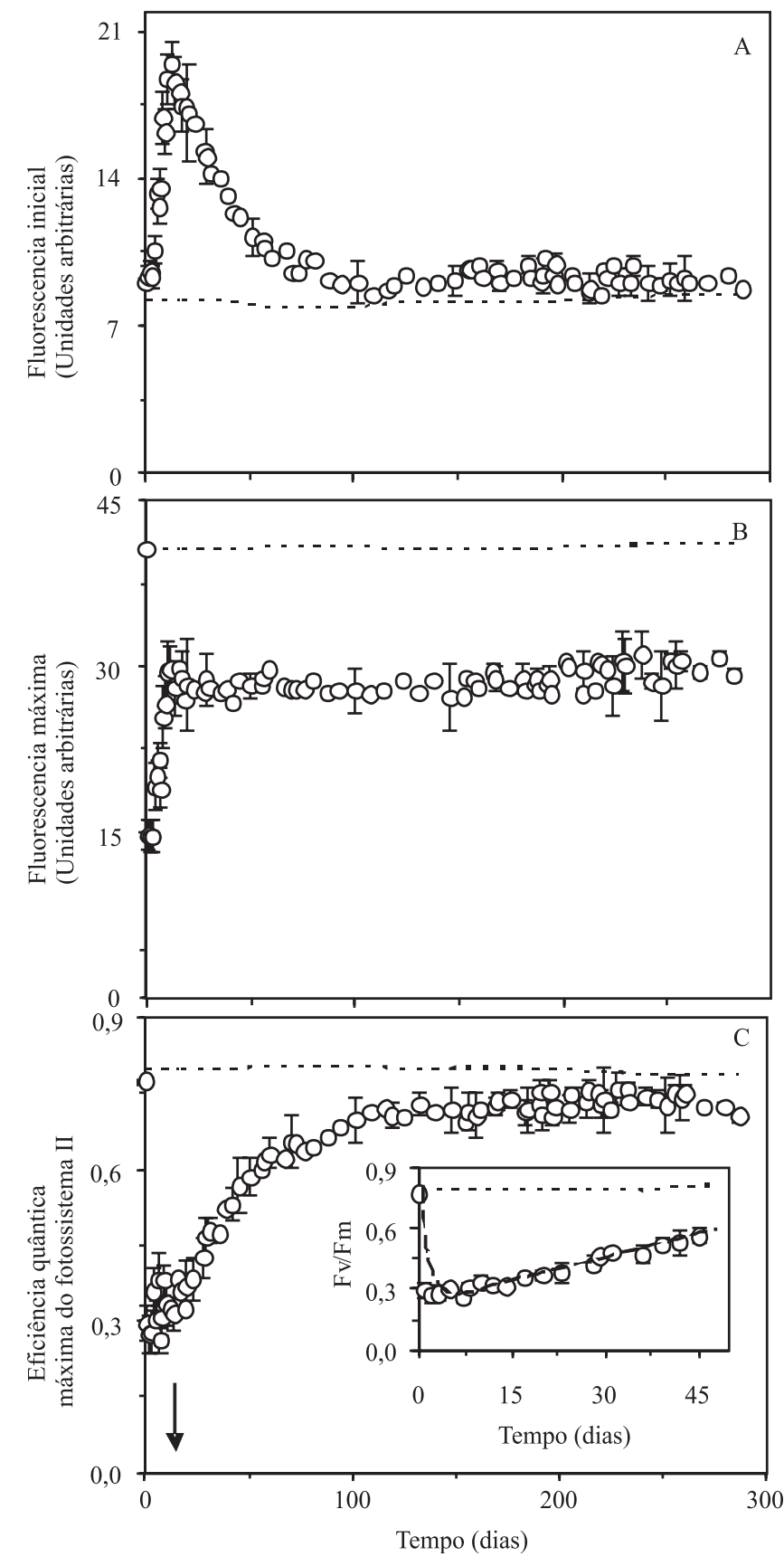

Figura 2. A, fluorescência inicial $\left(\mathrm{F}_{\mathrm{o}}\right)$; $\mathrm{B}$, fluorescência máxima $\left(\mathrm{F}_{\mathrm{m}}\right)$; e C, eficiência quântica máxima do fotossistema II $\left(\mathrm{F}_{\mathrm{v}} / \mathrm{F}_{\mathrm{m}}\right)$ em mudas de acariquara (Minquartia guianensis), em função do tempo de exposição à luz solar plena. As linhas tracejadas mostram os valores de fluorescência observados no controle. As barras verticais em cada símbolo indicam o erro-padrão da média. A seta vertical mostra o tempo no qual folhas produzidas no novo ambiente começaram a ser medidas. $\mathrm{O}$ destaque no painel em $\mathrm{C}$ mostra a queda nos valores $\mathrm{F}_{\mathrm{v}} / \mathrm{F}_{\mathrm{m}}$ nos primeiros dias no tratamento. até atingir valores máximos após quatro meses do início do processo de aclimatação. Em alta irradiância, os valores $\mathrm{F}_{\mathrm{v}} / \mathrm{F}_{\mathrm{m}}$ atingiram $93 \%$ dos valores observados no controle.

$\mathrm{O}$ aumento observado em $\mathrm{F}_{\mathrm{o}}$ após exposição à luz solar intensa é consistente com resultados encontrados por outros autores (Dias \& Marenco, 2006). Como a proteína $\mathrm{D}_{1}$ do fotossistema II (FSII) é o principal alvo da fotoinibição (Long et al., 1994), a exposição à alta irradiância de plantas desenvolvidas à sombra pode induzir um aumento de $\mathrm{F}_{\mathrm{o}}$, em razão do bloqueio da transferência de elétrons da plastoquinona A para a plastoquinona B, como resultado da inativação parcial da população do FSII (Gilmore et al., 1996). O declínio de $\mathrm{F}_{\mathrm{o}}$ depois da segunda semana nas plantas expostas ao sol indica recuperação da fotoinibição, pois nesse mesmo período observou-se também aumento nos valores de $\mathrm{F}_{\mathrm{v}} / \mathrm{F}_{\mathrm{m}}$. A redução de $\mathrm{F}_{\mathrm{m}}$ pode ser atribuída à dissipação não fotoquímica, via ciclo da xantofila, no qual a violaxantina é convertida em zeaxantina (Demmig-Adams \& Adams, 2006), bem como a inativação de uma fração dos fotossistemas 2 (FSII) que, quando inativos, contribuem para a dissipação de energia na forma de calor, mas não para a dissipação fotoquímica da energia radiante (Lee et al., 2001). A queda brusca nos valores de $\mathrm{F}_{\mathrm{v}} / \mathrm{F}_{\mathrm{m}}$ logo após transferência para luz solar plena é coerente com o fato de plantas desenvolvidas à sombra serem mais sensíveis à fotoinibição que plantas adaptadas a ambientes ensolarados (Kitao et al., 2000).

A $A_{\text {máx. }}$ das plantas aclimatadas aumentou em $90 \%$ em comparação ao controle (Tabela 1). De forma similar, a condutância estomática $\left(\mathrm{g}_{\mathrm{s}}\right)$ (medida em $\mathrm{CO}_{2}$ ambiente) e a $R_{d}$ foram também maiores em folhas aclimatadas ao sol. Ao contrário, o $\Theta$ e o teor de clorofila foram menores em plantas aclimatadas à alta luminosidade em comparação com o controle. Porém, não houve efeito significativo ( $p>0,05)$ entre os tratamentos (sol e sombra) nos valores $\Gamma$ e $\Phi$. Os valores de $A_{\text {máx. }}$ e $\Phi$ observados em plantas aclimatadas à luz solar plena estão dentro da faixa de valores encontrados em outras espécies da sucessão tardia, tais como Hydrophyllum virginianum, Quercus rubra e Aesculus glabra (Bazzaz \& Carlson, 1982). Marenco \& Vieira (2005) também encontraram valores de $\mathrm{A}_{\text {máx. }}, \Phi$ e $\Theta$ similares aos relatados no presente trabalho. Entretanto, os valores de $\Phi$ relatados no presente trabalho são menores que os valores máximos potenciais (em torno de 0,08) observados em plantas $\mathrm{C}_{3}$ em baixa concentração de $\mathrm{O}_{2}$ ou alto $\mathrm{C}_{\mathrm{i}}$ (Björkman, 1981). Essa discrepância deve-se ao fato de $\Phi$ ter sido determinado em concentrações ambiente de $\mathrm{CO}_{2}$ e $\mathrm{O}_{2}$ 
no presente trabalho. A condutância estomática $\left(\mathrm{g}_{\mathrm{s}}\right)$ pode influenciar $\Phi$ por meio de seu efeito em $\mathrm{C}_{\mathrm{i}}$, (Björkman, 1981); porém, isso não foi observado, pois embora $\mathrm{g}_{\mathrm{s}}$ tenha variado de 0,03 a $0,07 \mathrm{~mol} \mathrm{~m}^{-2} \mathrm{~s}^{-1}$, essa variação não influenciou $\Phi$ (Tabela 1).

$\mathrm{Na}$ alta irradiância, a transição da fotossíntese de limitada por $\mathrm{A}_{\mathrm{c}}$ para limitada por $\mathrm{A}_{\mathrm{j}}$ ocorreu em $\mathrm{C}_{\mathrm{i}}$ de $652 \mu \mathrm{mol} \mathrm{mol}^{-1}$, valor maior que o do controle, de $543 \mu \mathrm{mol} \mathrm{mol}{ }^{-1}$ (Figura 3). A diminuição nos valores de $\Theta$ no controle é indicação de menor investimento em proteínas da rubisco. Isso porque, quando esse investimento é reduzido, a transição de fotossíntese limitada por $\mathrm{A}_{\mathrm{c}}$ para limitada por $\mathrm{A}_{\mathrm{j}}$ ocorre mais rápido e o formato final da curva é mais truncado. Provavelmente, por isso os valores de $\Theta$ tendem a aumentar (transição pausada de $\mathrm{A}_{\mathrm{c}}$ para $\mathrm{A}_{\mathrm{j}}$ ) à proporção que plantas se aclimatam à alta irradiância (Ogren, 1993). Independentemente do tratamento de aclimatação à alta irradiância, o fator limitante da fotossíntese foi a velocidade de carboxilação da rubisco, o que está de acordo com os resultados de Sage \& Kubien (2007), que mostram que, exceto em temperaturas muito altas, a fotossíntese é mais comumente limitada pela atividade da rubisco.

A maior irradiância de compensação $\left(\mathrm{R}_{d} / \Phi\right)$ em plantas aclimatadas ao aberto é resultado de uma maior taxa de respiração $\left(R_{d}\right)$, o que é esperado para plantas desenvolvidas ao sol que apresentam um maior investimento em proteínas envolvidas no ciclo de Calvin (Björkman, 1981).

A aclimatação à luz teve um efeito positivo em $\mathrm{A}_{\text {pot., }}$, $\mathrm{V}_{\text {c-máx. }}$ e $\mathrm{J}_{\text {máx. }}$. Os valores de $\mathrm{V}_{\mathrm{c} \text {-máx. }}$ e $\mathrm{J}_{\text {máx. }}$ foram 37 e $50 \%$ maiores em alta irradiância que no controle (Tabela 1). Os valores de $\mathrm{V}_{\mathrm{c} \text {-máx. }}$ e $\mathrm{J}_{\text {máx. }}$ observados no presente trabalho estão dentro da faixa dos valores relatados por Wullschleger (1993). Aumentos em $\mathrm{A}_{\text {pot. }}, \mathrm{V}_{\mathrm{c} \text {-máx. }}$ e $\mathrm{J}_{\text {máx. }}$ em resposta à aclimatação à luz solar plena indica maior investimento em proteínas associadas à rubisco (Hikosaka \& Terashima, 1995) em detrimento do conteúdo proteico associado com os complexos coletores de luz, o que, por sua vez, explica a redução no teor de clorofila nas plantas aclimatadas à alta irradiância, em comparação ao controle não aclimatado.

A espessura da folha aumentou entre 50 (na base da folha fresca) e $100 \%$ (folha seca) nas plantas aclimatadas à alta irradiância, o que está de acordo com os resultados de Niinemets (1999). Porém, em Chenopodium album observou-se aumento em $\mathrm{A}_{\text {máx. }}$ sem aumento na espessura foliar (Oguchi et al., 2003). A relação clorofila a/b foi maior no ambiente com alta irradiância (Tabela 1), o que é consistente com o fato de plantas desenvolvidas ao sol investirem menos em proteínas associadas aos

Tabela 1. Fotossíntese máxima $\left(\mathrm{A}_{\text {máx. }}\right)$ e potencial $\left(\mathrm{A}_{\text {pot. }}\right)$, condutância estomática $\left(\mathrm{g}_{\mathrm{s}}\right)$, velocidade máxima de carboxilação da rubisco $\left(\mathrm{V}_{\mathrm{c} \text {-máx. }}\right)$, taxa máxima de transporte de elétrons $\left(\mathrm{J}_{\text {máx. }}\right)$, espessura foliar, altura, diâmetro do caule, clorofila $a$ e $b$ e relação clorofila $a / b$, carotenoides, relação clorofila $(a+b)$ /carotenoides, densidade estomática, comprimento da célula-guarda $(\mathrm{CG})$, respiração foliar $\left(\mathrm{R}_{\mathrm{d}}\right)$, rendimento quântico aparente $(\Phi)$, parâmetro de convexidade $(\Theta)$, ponto de compensação por luz $\left(\mathrm{R}_{\mathrm{d}} / \Phi\right)$, ponto de compensação de $\mathrm{CO}_{2}(\Gamma)$ e área foliar específica (AFE) de mudas de acariquara (Minquartia guianensis) aclimatadas a irradiâncias diferentes ${ }^{(1)}$.

\begin{tabular}{|c|c|c|c|}
\hline Variáveis medidas & $\mathrm{n}$ & Controle (plantas desenvolvidas à sombra) & Plantas em alta irradiância \\
\hline $\mathrm{A}_{\text {máx. }}\left(\mu \mathrm{mol} \mathrm{m} \mathrm{m}^{-2} \mathrm{~s}^{-1}\right)$ & 4 & $2,72 \pm 0,29 b$ & $5,17 \pm 0,59 a$ \\
\hline $\mathrm{A}_{\text {pot. }}\left(\mu \mathrm{mol} \mathrm{m} \mathrm{m}^{-2} \mathrm{~s}^{-1}\right)$ & 4 & $8,34 \pm 0,18 b$ & $12,60 \pm 1,33 \mathrm{a}$ \\
\hline $\mathrm{g}_{\mathrm{s}}\left(\mathrm{mol} \mathrm{m}^{-2} \mathrm{~s}^{-1}\right)$ & 4 & $0,03 \pm 0,01 b$ & $0,07 \pm 0,00 \mathrm{a}$ \\
\hline $\mathrm{V}_{\mathrm{c}-\text { máx. }}$ a $25^{\circ} \mathrm{C}\left(\mu \mathrm{mol} \mathrm{m} \mathrm{m}^{-2} \mathrm{~s}^{-1}\right)$ & 4 & $15,24 \pm 2,07 b$ & $20,86 \pm 1,43 a$ \\
\hline $\mathrm{J}_{\text {máx. }}$ a $25^{\circ} \mathrm{C}\left(\mu \mathrm{mol} \mathrm{m} \mathrm{m}^{-2}\right)$ & 4 & $31,97 \pm 2,12 b$ & $48,05 \pm 3,83 a$ \\
\hline Espessura - folha seca (mm) & 10 & $0,05 \pm 0,007 \mathrm{~b}$ & $0,10 \pm 0,013 \mathrm{a}$ \\
\hline Espessura - folha fresca (mm) & 10 & $0,08 \pm 0,006 \mathrm{~b}$ & $0,12 \pm 0,012 \mathrm{a}$ \\
\hline Altura (m) & 10 & $27,38 \pm 2,93 b$ & $43,58 \pm 3,10 \mathrm{a}$ \\
\hline Diâmetro do caule (mm) & 10 & $2,39 \pm 0,21 b$ & $6,14 \pm 0,14 a$ \\
\hline Clorofila $a\left(\mathrm{mg} \mathrm{m}^{-2}\right)$ & 10 & $371,65 \pm 24,71 \mathrm{a}$ & $236,37 \pm 47,13 b$ \\
\hline Clorofila $b\left(\mathrm{mg} \mathrm{m}^{-2}\right)$ & 10 & $155,98 \pm 13,37 \mathrm{a}$ & $93,15 \pm 20,65 b$ \\
\hline Clorofila $a / b$ & 10 & $2,38 \pm 0,11 b$ & $2,55 \pm 0,15 \mathrm{a}$ \\
\hline Carotenoides $\left(\mu \mathrm{mol} \mathrm{m}{ }^{-2}\right)$ & 10 & $172,02 \pm 10,17 \mathrm{a}$ & $146,42 \pm 22,47 b$ \\
\hline Relação clorofila $(a+b) /$ carotenoides & 10 & $3,07 \pm 0,09 \mathrm{a}$ & $2,25 \pm 0,23 b$ \\
\hline Densidade estomática $\left(\mathrm{n}^{\mathrm{o}} \mathrm{mm}^{-2}\right)$ & 10 & $159,42 \pm 3,54 b$ & $301,10 \pm 21,65 \mathrm{a}$ \\
\hline Comprimento da CG $(\mu \mathrm{m})$ & 10 & $12,12 \pm 0,83 \mathrm{a}$ & $10,87 \pm 0,37 b$ \\
\hline $\mathrm{R}_{\mathrm{d}}\left(\mu \mathrm{mol} \mathrm{m} \mathrm{m}^{-2} \mathrm{~s}^{-1}\right)$ & 4 & $0,12 \pm 0,07 \mathrm{~b}$ & $0,54 \pm 0,26 a$ \\
\hline$\Phi\left[\mathrm{mol}\left(\mathrm{CO}_{2}\right) \mathrm{mol}^{-1}\right.$ (fótons) $]$ & 4 & $0,035 \pm 0,008 \mathrm{a}$ & $0,030 \pm 0,005 \mathrm{a}$ \\
\hline$\Theta$ (adimensional) & 4 & $0,85 \pm 0,041 \mathrm{a}$ & $0,78 \pm 0,034 b$ \\
\hline $\mathrm{R}_{\mathrm{d}} / \Phi\left(\mu \mathrm{mol} \mathrm{m} \mathrm{m}^{-2} \mathrm{~s}^{-1}\right)$ & 4 & $3,60 \pm 2,16 b$ & $18,24 \pm 7,89 \mathrm{a}$ \\
\hline$\left(\mu \mathrm{mol} \mathrm{mol}{ }^{-1}\right)$ & 4 & $99,41 \pm 8,58 \mathrm{a}$ & $89,61 \pm 10,40 \mathrm{a}$ \\
\hline $\operatorname{AFE}\left(\mathrm{m}^{2} \mathrm{~kg}^{-1}\right)$ & 10 & $21,470 \pm 1,23 \mathrm{a}$ & $12,559 \pm 1,09 \mathrm{~b}$ \\
\hline
\end{tabular}

${ }^{(1)}$ Médias \pm desvio-padrão seguidas de letras iguais nas linhas não diferem entre si pelo teste t, a 5\% de probabilidade. 
complexos coletores de luz (Björkman, 1981). Ao contrário, a relação entre clorofila total e carotenoides foi maior em plantas sombreadas que nas aclimatadas à alta luminosidade (Tabela 1), o que é consistente com o fato de os carotenoides terem um papel relevante na dissipação de energia na forma de calor (Demmig-Adams \& Adams, 2006). Foram observados estômatos somente na superfície abaxial da folha, com densidade estomática maior em folhas aclimatadas ao ambiente ensolarado que no controle. Plantas aclimatadas à luz intensa apresentaram maior altura $(160 \%)$ e diâmetro do caule $(256 \%)$, porém menor AFE $(60 \%)$ que as plantas do controle. Isso é uma indicação
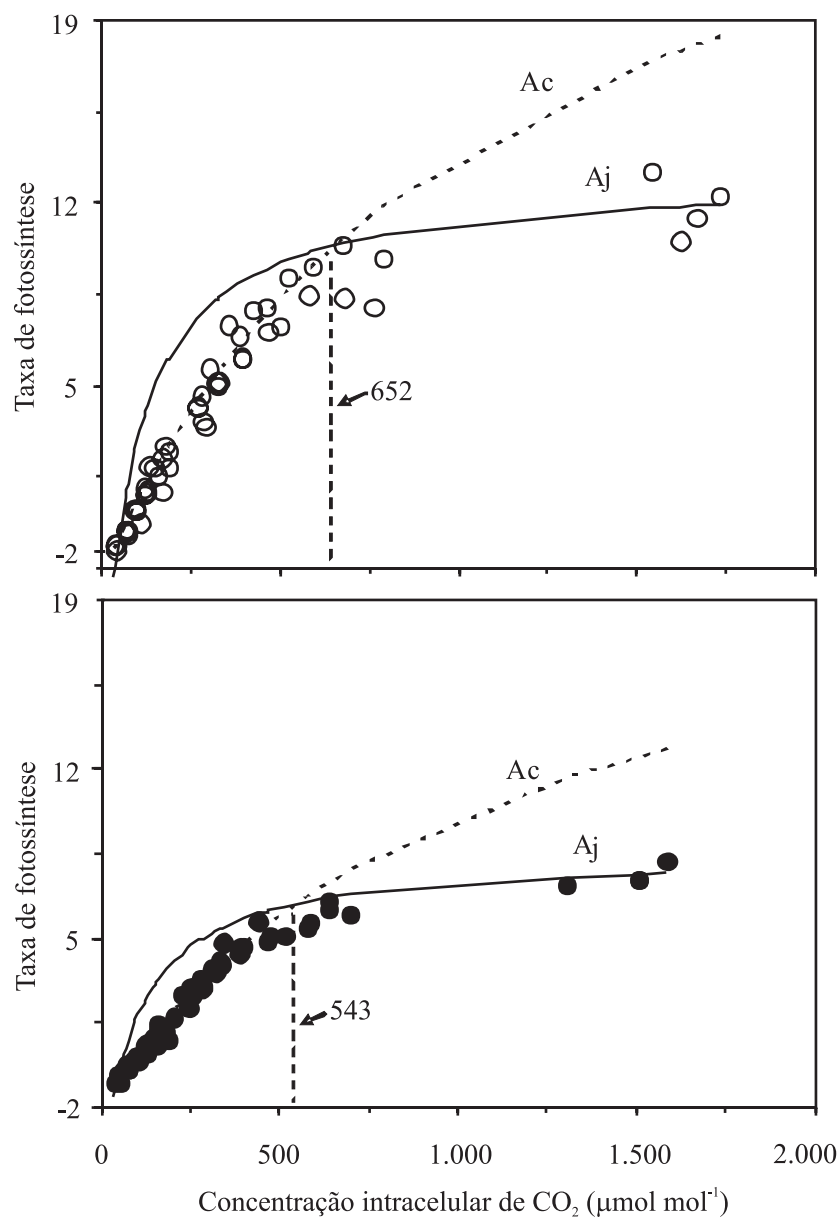

Figura 3. Taxa de fotossíntese (A) em função da concentração de $\mathrm{CO}_{2}$ intercelular em folhas de acariquara (Minquartia guianensis) aclimatadas à luz solar plena (o) e no controle (•). A curva tracejada mostra a limitação da fotossíntese imposta pela taxa de carboxilação da rubisco $\left(\mathrm{A}_{c}\right)$. A linha contínua indica a limitação da fotossíntese imposta pelo transporte de elétrons $\left(\mathrm{A}_{\mathrm{j}}\right)$. A linha tracejada vertical mostra o valor de $\mathrm{C}_{\mathrm{i}}$ em que ocorre a transição de fotossíntese limitada por $\mathrm{A}_{c}$ para a limitada por $\mathrm{A}_{\mathrm{j}}$. Os números (dentro dos gráficos) mostram os valores de $\mathrm{C}_{\mathrm{i}}$ em $\mu \mathrm{mol} \mathrm{mol}^{-1}$. de que, embora as plantas expostas à irradiância intensa tenham sofrido estresse severo logo após a transferência para o novo ambiente, no longo prazo a aclimatação resultou em maiores ganhos de biomassa, inferidos pelo aumento em altura e diâmetro do caule.

A densidade estomática e o comprimento das CG observados no presente trabalho para acariquara estão dentro da faixa de valores relatados por Hetherington \& Woodward (2003), que observaram de 50 a 900 estômatos $\mathrm{mm}^{-2}$ e comprimento de CG de 5 a $80 \mu \mathrm{m}$. A maior densidade estomática encontrada em folhas produzidas no ambiente ensolarado está de acordo com estudos que mostram aumento da densidade estomática proporcional ao aumento da irradiância (Voleníková \& Tichá, 2001). Aparentemente, a alta densidade estomática pode aumentar o acúmulo da biomassa (Al Afas et al., 2006), provavelmente em razão do uso mais eficiente da água, uma vez que estômatos pequenos podem abrir e fechar-se mais rapidamente que estômatos maiores (Hetherington \& Woodward, 2003).

\section{Conclusões}

1. As folhas de acariquara (Minquartia guianensis) desenvolvidas à sombra sofrem fotoinibição severa e, em alguns casos, até foto-oxidação. Porém, a perda prematura de folhas é compensada pela produção de folhas novas com alta capacidade fotossintética.

2. A produção de folhas novas fisiologicamente adaptadas ao novo ambiente é a principal estratégia de aclimatação à alta irradiância dessa espécie.

\section{Agradecimentos}

Ao Ministério da Ciência e Tecnologia, à Fundação de Amparo à Pesquisa do Estado do Amazonas e ao projeto CTPetro, pelo apoio financeiro; ao Conselho Nacional de Desenvolvimento Científico e Tecnológico e à Coordenação de Aperfeiçoamento de Pessoal de Nível Superior, pelas bolsas concedidas.

\section{Referências}

AL AFAS, N.; MARRON, N.; CEULEMANS, R. Clonal variation in stomatal characteristics related to biomass production of 12 poplar (Populus) clones in a short rotation coppice culture. Environmental and Experimental Botany, v.58, p.279-286, 2006.

BAZZAZ, F.A.; CARLSON, R.W. Photosynthetic acclimation to variability in the light environment of early and late successional plants. Oecologia, v.54, p.313-316, 1982. 
BJÖRKMAN, O. Responses to different quantum flux densities. In: LANGE, O.L.; NOBEL, P.S.; OSMOND, C.B.; ZIEGLER, H. (Ed.). Physiological Plant Ecology. Berlin: Springer-Verlag, 1981. p.57-108. (Encyclopedia of Plant Physiology. New Series, 12A).

CHOUDHURY, N.K.; BEHERA, R.K. Photoinhibition of photosynthesis: role of carotenoids in photoprotection of chloroplast constituents. Photosynthetica, v.39, p.481-488, 2001.

DEMMIG-ADAMS, B.; ADAMS, W.W. Photoprotection in an ecological context: the remarkable complexity of thermal energy dissipation. New Phytologist, v.172, p.11-21, 2006.

DIAS, D.P.; MARENCO, R.A. Photoinhibition of photosynthesis in Minquartia guianensis and Swietenia macrophylla inferred by monitoring the initial fluorescence. Photosynthetica, v.44, p.235-240, 2006.

FARQUHAR, G.D.; VON CAEMMERER, S.V.; BERRY, J.A. A biochemical model of photosynthetic $\mathrm{CO}_{2}$ assimilation in leaves of $\mathrm{C}_{3}$ species. Planta, v.149, p.78-90, 1980.

GENTY, B.; BRIANTAIS, J.M.; BAKER, N.R. The relationship between the quantum yield of photosynthetic electron-transport and quenching of chlorophyll fluorescence. Biochimica et Biophysica Acta, v.990, p.87-92, 1989.

GILMORE,A.M.;HAZLETT,T.L.;DEBRUNNER,P.G.;GOVINDJEE. Comparative time-resolved photosystem II chlorophyll a fluorescence analyses reveal distinctive differences between photoinhibitory reaction center damage and xanthophyll cycle-dependent energy dissipation. Photochemistry and Photobiology, v.64, p.552-563, 1996.

HETHERINGTON, A.M.; WOODWARD, F.I. The role of stomata in sensing and driving environmental change. Nature, v.424, p.901-908, 2003.

HIKOSAKA, K.; TERASHIMA, I. A model of the acclimation of photosynthesis in the leaves of $\mathrm{C}_{3}$ plants to sun and shade with respect to nitrogen use. Plant, Cell \& Environment, v.18, p.605-618, 1995.

HOUTER, N.C.; PONS, T.L. Gap size effects on photoinhibition in understorey saplings in tropical rainforest. Plant Ecology, v.179, p.43-51, 2005.

JESUS, S.V. de; MARENCO, R.A. O SPAD-502 como alternativa para a determinação dos teores de clorofila em espécies frutíferas. Acta Amazônica, v.38, p.815-818, 2008.

KITAO, M.; LEI, T.T.; KOIKE, T.; TOBITA, H.; MARUYAMA, Y. Susceptibility to photoinhibition of three deciduous broadleaf tree species with different successional traits raised under various light regimes. Plant, Cell \& Environment, v.23, p.81-89, 2000.

KURSAR, T.A.; COLEY, P.D. Contrasting modes of light acclimation in two species of the rainforest understory. Oecologia, v.121, p.489-498, 1999.

LAISK, A.; EICHELMANN, H.; OJA, V.; RASULOV, B.; PADU, E.; BICHELE, I.; PETTAI, H.; KULL, O. Adjustment of leaf photosynthesis to shade in a natural canopy: rate parameters. Plant, Cell \& Environment, v.28, p.375-388, 2005.

LEE,H.Y.; HONG, Y.N.; CHOW, W.S. Photoinactivation of photosystem II complexes and photoprotection by non-functional neighbours in Capsicum annuun L. leaves. Planta, v.212, p.332-342, 2001.
LONG, S.P.; BERNACCHI, C.J. Gas exchange measurements, what can they tell us about the underlying limitations to photosynthesis? Procedures and sources of error. Journal of Experimental Botany, v.54, p.2393-2401, 2003.

LONG, S.P.; HUMPHRIES, S.; FALKOWSKI, P.G. Photoinhibition of photosynthesis in nature. Annual Review of Plant Physiology and Plant Molecular Biology, v.45, p.633-662, 1994.

LOVELOCK, C.E.; JEBB, M.; OSMOND, C.B. Photoinhibition and recovery in tropical plant species: response to disturbance. Oecologia, v.97, p.297-307, 1994.

MARENCO, R.A.; GONÇALVES, J.F.C.; VIEIRA, G. Leaf gas exchange and carbohydrates in tropical trees differing in successional status in two light environments in central Amazonia. Tree Physiology, v.21, p.1311-1318, 2001.

MARENCO, R.A.; VIEIRA, G. Specific leaf area and photosynthetic parameters of tree species in the forest understorey as a function of the microsite light environment in Central Amazonia. Journal of Tropical Forest Science, v.17, p.265-278, 2005.

MEDLYN, B.E.; BADECK, F.W.; DE PURY, D.G.G.; BARTON, C.V.M.; BROADMEADOW, M.; CEULEMANS, R.; DE ANGELIS, P.; FORSTREUTER, M.; JACH, M.E.; KELLOMÄKI, S.; LAITAT, E.; MAREK, M.; PHILIPPOT, S.; REY, A.; STRASSEMEYER, J.; LAITINEN, K.; LIOZON, R.; PORTIER, B.; ROBERNTZ, P.; WANG, K.; JSTBID, P.G. Effects of elevated [CO2] on photosynthesis in European forest species: a meta-analysis of model parameters. Plant, Cell \& Environment, v.22, p.1475-1495, 1999.

NIINEMETS, Ü. Research review. Components of leaf dry mass per area - thickness and density - alter leaf photosynthetic capacity in reverse directions in woody plants. New Phytologist, v.144, p.35-47, 1999.

OGREN, E. Convexity of the photosynthetic light-response curve in relation to intensity and direction of light during growth. Plant Physiology, v.101, p.1013-1019, 1993.

OGUCHI, R.; HIKOSAKA, K.; HIROSE, T. Does the photosynthetic light-acclimation need change in leaf anatomy? Plant, Cell \& Environment, v.26, p.505-512, 2003.

OGUCHI, R.; HIKOSAKA, K.; HIROSE, T. Leaf anatomy as a constraint for photosynthetic acclimation: differential responses in leaf anatomy to increasing growth irradiance among three deciduous trees. Plant, Cell \& Environment, v.28, p.916-927, 2005.

SAGE, R.F.; KUBIEN, D.S. The temperature response of $\mathrm{C}_{3}$ and $\mathrm{C}_{4}$ photosynthesis. Plant, Cell \& Environment, v.30, p.1086-1106, 2007.

VOLENÍKOVÁ, M.; TICHÁ, I. Insertion profiles in stomatal density and sizes in Nicotiana tabacum L. plantlets. Biology Plantarum, v.44, p.161-165, 2001.

WULLSCHLEGER, S.D. Biochemical limitations to carbonassimilation in $\mathrm{C}_{3}$ plants - a retrospective analysis of the $\mathrm{A} / \mathrm{C}_{\mathrm{i}}$ curves from 109 species. Journal of Experimental Botany, v.44, p.907-920, 1993.

$\overline{\text { Recebido em } 17 \text { de fevereiro de } 2009 \text { e aprovado em } 3 \text { de julho de } 2009}$ 